COMÉRCIO (TRANS)ATLÂNTICO: As rabidantes cabo-verdianas e o mercado informal brasileiro ${ }^{1}$

(TRANS)ATLANTIC COMMERCE: The Cape Verde travelling salesmen and the Brazilian informal market;

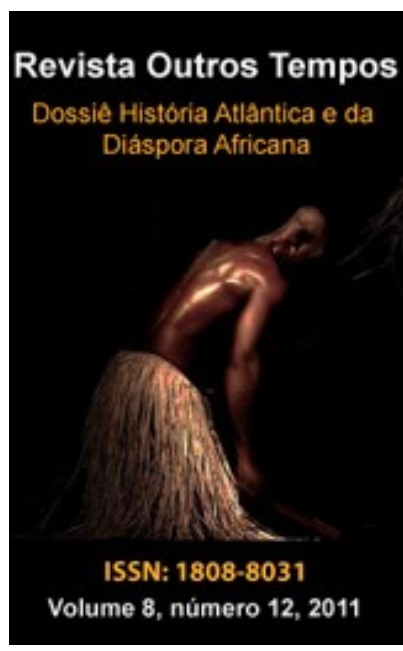

TATIANA RAQUEL REIS SILVA Doutoranda PPGH-UFBA Salvador, BA-Brasil tatianaraquel.reis@gmail.com

Resumo: o presente texto busca analisar o comercio (trans)atlântico das rabidantes cabo-verdianas no mercado brasileiro. Essas mulheres possuem uma grande importância para a econômica local e tem possibilitado intensas trocas entre os dois países. No Brasil, os produtos adquiridos são em sua maioria roupas, calçados e bijuterias, vindos de Fortaleza no Estado do Ceará. Vale destacar, que tanto a compra no território brasileiro, quanto a comercialização destes produtos em Cabo Verde, ocorre no âmbito informal, em geral, nas feiras e mercados.

Palavras-chave: Relações comerciais. Informalidade. Rabidantes. Cabo Verde. Brasil.

Abstract: This text analyzes the trade (trans)atlantic cape verdean rabidantes in the Brazilian market. These women have a great importance to the local economy and have enabled intense exchanges between the two countries. In Brazil, the products are mostly purchased clothing, shoes and jewelry, from Fortaleza in Ceará. It is worth noting that both the buying in the Brazilian territory, as the marketing of these products in Cape Verde, occurs in informality, usually at fairs and markets.

Key-words: Business relationship. Informality. Rabidantes. Cape Verde. Brazil.

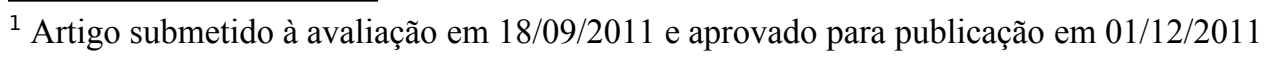


O Brasil tem estabelecido fortes vínculos comerciais com Cabo Verde nos últimos anos, especialmente por intermédio das chamadas rabidantes ${ }^{2}$, mulheres que compram e vendem produtos em ruas, lojas e mercados e que em nosso país são conhecidas como "sacoleiras". O comércio informal por elas desenvolvido tem servido como um dos principais eixos de sustentação da economia cabo-verdiana e possibilitado intensas trocas nos dois lados do atlântico.

As rabidantes são responsáveis pela venda de inúmeros produtos que vão desde gêneros alimentícios, como peixe, verduras e legumes, até roupas, calçados e bijuterias. Esses artigos podem ser adquiridos em outros países africanos e, também, na Holanda, Estados Unidos e Brasil. No território nacional, a efetivação das compras se dá pela grande procura por peças de vestuário e os principais destinos dessas comerciantes são o Estado de São Paulo e o Ceará, este último tem ganhado destaque em função dos vôos diretos que ligam Fortaleza e a Cidade de Praia, capital de Cabo Verde.

Com o advento da política externa brasileira voltada para a África, foi possível perceber o estabelecimento de inúmeros acordos diplomáticos que buscaram estreitar as relações comerciais com países africanos. Nesse contexto, Cabo Verde ganhou destaque e os discursos de irmandade no além-mar, assim como de proximidades culturais, fizeram-se presentes, sobretudo, entre aqueles que viveram sob o jugo colonial português. Todavia, almejava-se concretizar laços comerciais formais e o trabalho das rabidantes foge à regra estabelecida por esses governos.

Os debates entre práticas formais e informais e, consequentemente, o pagamento ou não de tributos tem possibilitado medidas cada vez mais coercitivas tanto no Brasil quanto em Cabo Verde, afetando diretamente a atividade dessas mulheres. No entanto, a informalidade tem se configurado como um fenômeno de grande projeção nos dois países e ao longo dos anos vem ganhando cada vez mais adeptos. Como será possível perceber, esse setor tem uma grande importância tanto na economia brasileira quanto cabo-verdiana.

Dessa forma, o presente texto visa analisar a efetivação de compras pelas rabidantes cabo-verdianas no mercado informal brasileiro, destacando os principais locais de aquisição dos produtos, assim como a dinâmica de comercialização no seu país

\footnotetext{
${ }^{2}$ Apesar de o português ser a língua oficial, em Cabo Verde, as pessoas cotidianamente falando o crioulo, que surgiu como língua franca ao longo do processo de colonização, resultando do intenso contato entre os colonizadores e as populações nativas da região da Guiné. Assim, rabidantes em crioulo cabo-verdiano significa dar a volta, desenroscar-se e é utilizado para designar alguém que é muito hábil em convencer os outros.
} 
de origem. Para isso, faz-se necessária a contextualização histórica e social de Cabo Verde, assim como uma breve discussão acerca da política externa brasileira e a consequente aproximação entre os dois países. Também será dedicado um espaço para o debate sobre as medidas impostas por esses governos, frente ao aumento do comércio informal.

\section{Contextualização histórico-social}

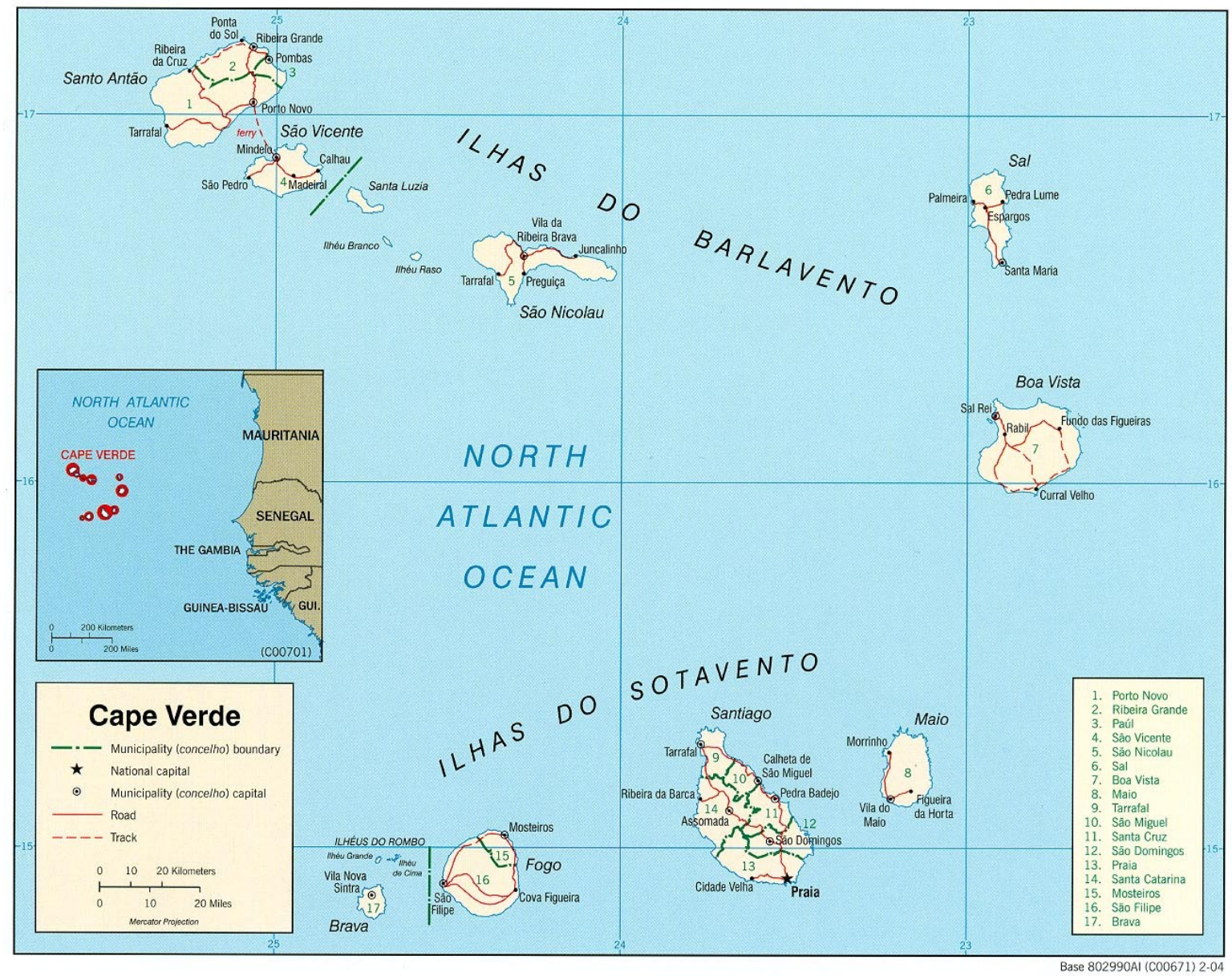

As Ilhas de Cabo Verde foram descobertas pelos portugueses em 1460. De acordo com Andrade (1995), era intenção dos colonizadores possibilitar o povoamento branco, como nos Açores e na Ilha da Madeira, mas foram as diversas etnias existentes na Costa da Guiné que contribuíram para o povoamento do país. A mestiçagem originou a população crioula que marca a sociedade atual. O povoamento ocorreu de forma lenta e foi realizado através do processo de doação de terras a europeus que procediam ao seu cultivo e à criação de animais, utilizando a mão-de-obra escrava. 
A escassez de recursos que caracteriza o país advém desde o período colonial. A política administrativa não fixou como objetivo o desenvolvimento da agricultura e das condições de estocagem do solo. A desastrosa gestão do meio natural com a criação de cabras nas encostas constituiu um fator de progressiva erosão do solo, assim como a subutilização das terras irrigáveis, para além das necessidades dos colonos. Manuela Cardoso (2007) assinala que o governo português nunca demonstrou muito interesse em desenvolver o povoamento efetivo no arquipélago e muito menos se empenhou na valorização de um espaço insular com riquezas limitadas.

O arquipélago é formado por dez ilhas ${ }^{3}$, de origem vulcânica, que possuem características naturais, socioculturais e econômicas diferentes. Todas sofrem influência do Sahel, o que lhes confere um clima árido ou semi-árido. Os ventos secos, vindos do continente africano, contribuem para a salinização do solo. A consequente erosão e o escoamento das chuvas para o mar não tem possibilitado a reconstituição dos lençóis freáticos - apenas $13 \%$ da água superficial se infiltra no solo permitindo a sua alimentação. Dentre todas as ilhas, a de Santiago ganhou maior atenção desde o período de colonização, por possuir o clima mais propício para o estabelecimento dos colonos e atualmente concentrar metade da população do país ${ }^{4}$.

Cabo Verde cumpriu a função de agenciadora no tráfico atlântico, desde a sua descoberta até o final do século XIX. Devido a sua estratégica posição geográfica, situada entre os três continentes (Europa, África e América), constituiu uma plataforma comercial de apoio à expansão portuguesa, funcionando como entreposto de escravos e como local de abastecimento de água. Os mercadores que iam à procura de escravos também compravam algodão, peles e sebo e abasteciam a ilha de produtos de primeiras necessidades, como milho e arroz (trazidos da Guiné), azeite, vinho e farinha de trigo (advindos da Europa).

A situação de pobreza que caracterizava a maioria dos habitantes e o enriquecimento de uma minoria conduziu a uma sociedade hierarquizada em categorias sociais bastante fechadas. Na primeira metade do século XVII, floresceu uma classe de "senhores brancos" que, embora constituíssem um grupo restrito, detentores do poder político, dedicavam-se a exploração e comercialização de algodão, tecidos e outros produtos. Mas a perda da exclusividade do tráfico de escravos na região, as constantes

\footnotetext{
${ }^{3}$ São elas: Santo Antão, São Vicente, São Nicolau, Santa Luzia (única ilha não habitada), Sal, Boavista, Santiago, Maio, Fogo e Brava.

${ }^{4}$ É na Ilha de Santiago que está localizada a capital do país, a Cidade de Praia.
} 
investidas dos franceses, ingleses e holandeses e a seca foram fatores que determinaram o declínio nesse tipo de economia ao longo dos séculos XVII e XVIII.

Com a abolição da escravatura, o país perdeu a sua vantagem estratégica e viu desaparecer os dividendos econômicos que provinham do tráfico escravista; a agropecuária para exportação, que exigia a renovação da mão-de-obra escrava, cedeu lugar à agricultura de subsistência e, consequentemente, transformou as grandes propriedades em pequenas porções de terra, utilizadas para produção em escala reduzida. No entanto, a cultura de subsistência não conseguiu responder às necessidades da população, ocasionando um novo processo de recessão.

Ao longo de todo o século XIX, o país foi marcado por longos ciclos de decadência. O império português, profundamente abalado pela nova formatação do comércio internacional, tentou imprimir dinâmicas novas às relações com suas colônias na África. Cabo Verde sofreu os reveses dessa reconfiguração na economia colonial, perdendo sua importância enquanto base de sustentação comercial. As constantes crises desencadearam a emigração em massa de cabo-verdianos para os EUA, Guiné, Senegal, Holanda e Portugal e uma emigração forçada para São Tomé e Príncipe, como saída para a situação calamitosa em que o país se encontrava, fruto da administração colonial desastrosa. As remessas dos emigrantes passaram a ser uma saída válida para a manutenção das famílias e se transformaram em uma importante fonte de sobrevivência.

Não obstante, com o apoio da Igreja e a consequente renovação do interesse pelo arquipélago, já no início do século $\mathrm{XX}$, foi-se criando estruturas sociais que se mantiveram até a independência. Nesse contexto, surgiram três classes sociais distintas, com cultura e interesses econômicos diferenciados: uma pequena aristocracia e grande burguesia, a pequena burguesia mestiça e a população cabo-verdiana que constituía $90 \%$ do total de habitantes. A pequena aristocracia e a grande burguesia eram compostas pelas classes sociais que viviam de acordo com o estilo de vida europeu em grandes mansões, gerindo os seus interesses econômicos. Eram os descendentes dos senhores traficantes de escravos.

A pequena burguesia mestiça, cujos recursos provinham da atividade comercial, do cultivo de pequenas parcelas da terra e da atividade artesanal, constituía a classe média. Os filhos dessa pequena burguesia conseguiram, progressivamente, ter acesso ao ensino de qualidade, em alguns casos fora do país, e ocupavam pequenos cargos da administração pública. A grande ambição desse grupo, de acordo com Manuela Cardoso 
(2007), era tornar-se também proprietária de terras, assumindo privilégios sociais semelhantes à primeira classe e rejeitando os valores culturais africanos.

Por fim, a classe que representava a maioria da população, o verdadeiro povo: trabalhadores não qualificados, pescadores, rendeiros, agricultores sem terra, micro-proprietários e pequenas comerciantes, estas últimas em sua maioria mães chefes de família, resultado direto do grande fluxo de emigração masculina. Nesse segmento encontramos um número significativo de rabidantes. Apesar da independência em 1975, os cinco séculos de ocupação portuguesa moldaram a sociedade cabo-verdiana. Nesse processo, a língua e a religião cristã foram introduzidas e os aspectos culturais africanos subalternizados em função dos interesses da metrópole.

A partir dos anos de 1940, observamos uma proliferação de movimentos emancipatórios na Ásia e na África, reforçados, dentre outros acontecimentos, pelo desmembramento das potências européias, fundação, em 1945, da Organização das Nações Unidas - ONU - e a consagração dos "Direitos dos Povos", em 1946. Nas primeiras décadas do século XX, o mundo português presenciava uma propagação de associações recreativas e culturais e sindicatos com tons de protestos, como Associação dos Estudantes, Partido Nacional Africano, Casa de África, Casa dos Estudantes Africanos. Esses movimentos foram impulsionados por jovens oriundos das diferentes colônias, que deram continuidade aos seus estudos na metrópole e voltaram para seus países de origem instituindo as lutas emancipacionistas ${ }^{5}$.

Nos anos de 1950, também emergiram várias outras organizações, dentre eles o Movimento de Libertação Nacional das Colônias Portuguesas (MLNCP) e o Partido Africano da Independência (PAI), que deu origem, em 1956, ao Partido Africano da Independência da Guiné e Cabo Verde (PAIGC). Foi a partir dos movimentos contestatórios e, consequentemente, do fortalecimento desses partidos, que se iniciou um longo período de críticas e denúncias referentes ao descaso e estado de miséria que o governo português havia relegado as suas, então, colônias, culminando com a independência do país ${ }^{6}$.

\section{A aproximação comercial entre Brasil e Cabo Verde}

\footnotetext{
${ }^{5}$ Dentre aqueles que ganharam maior destaque, temos: Amilcar Cabral - guineense -, Mario Pinto de Andrade e Agostinho Neto - angolanos - e Alda do Espírito Santo - santomeense.

${ }^{6} \mathrm{O}$ contexto que marcou a independência de Cabo Verde é permeado por intensos debates, com destaque para as desavenças que marcaram o rompimento com a Guiné. Infelizmente, essa é uma questão que extrapola o objetivo do presente texto. Para uma visão mais aprofundada, ver Fernandes (2006) e Moniz (2009).
} 
No tópico anterior, foi possível analisar o contexto histórico e social de Cabo Verde, o que contribuiu para um melhor entendimento do processo de formação dessa sociedade assim como as suas problemáticas atuais. Como observado, no âmbito econômico, a escassez de recursos e o baixo poder da agricultura garantiram a atividade comercial um lugar de significativa importância. No que tange às relações sociais, a maioria da população cabo-verdiana vive alheia a todo e qualquer benefício social. De acordo com o censo de 2000, o país possuía 434.625 habitantes, sendo que $45 \%$ da população estava abaixo da linha da pobreza, $30 \%$ era considerada pobre e $15 \%$ muito pobre.

A partir desse quadro podemos entender o porquê do número significativo de trabalhadores, que sem maiores qualificações, voltam-se para as atividades informais, como é o caso das rabidantes. Desde a sua independência, em especial a partir dos anos 1990, Cabo Verde vem adotando, como estratégia de desenvolvimento, a inserção de forma dinâmica na economia mundial, com o intuito de solucionar um dos seus principais problemas: proporcionar emprego e renda a uma grande parcela da população. Na primeira fase de implementação do Plano Nacional de Luta contra a Pobreza, ficou definido o combate à pobreza no grupo de mulheres, particularmente, entre aquelas chefes de família ${ }^{7}$, através da sua integração nos círculos econômicos, alfabetização e formação profissional, reforço da educação e da saúde.

De acordo com Grassi (2003), as mulheres representam cerca de 64\% dos analfabetos no país, sobretudo, aquelas que vivem no meio rural. Ao analisar os dados do Documento de Estratégia de Crescimento e Redução da Pobreza (DECRP), Furtado (2008) destaca que a porcentagem das mulheres chefes de família desempregadas atinge $61 \%$ contra $41 \%$ dos homens. Apesar do relativo crescimento econômico observado nos últimos anos, as disparidades sociais e econômicas continuaram. Como forma de tentar sanar essas deficiências, o governo cabo-verdiano tem adotado medidas estratégicas de inserção na economia internacional. Dessa forma, foi criada a Comunidade Econômica dos Estados da África Oeste (CEDEAO), cujo objetivo era possibilitar a cooperação e a integração, visando à melhoria das condições de vida das populações e o desenvolvimento ${ }^{8}$.

No que se refere ao comércio exterior, a União Europeia constitui o principal parceiro em importação e exportação com a região. Em segundo lugar podemos destacar

\footnotetext{
${ }^{7}$ Aproximadamente $41,7 \%$ das famílias cabo-verdianas são chefiadas por mulheres.

${ }^{8}$ Compõem a CEDEAO: Cabo Verde, Libéria, Mali, Niger, Nigéria, Senegal, Serra Leoa, Gana, Togo, Benin, Burkina Fasso, Costa do Marfim, Gâmbia, Guiné e Guiné-Bissau.
} 
os Estados Unidos, seguido pelo Brasil, Índia, China e Coréia do Sul. No caso brasileiro, a relação de cooperação advinda desde o período colonial, por intermédio do comércio atlântico de escravos para as Américas, ganhou novos ares entre os anos de 1940 e 1950. Essa aproximação caracterizava-se pelo discurso de fraternidade e paternalismo que Portugal desempenhara tanto em solo brasileiro como nas suas possessões no continente africano. Naquela conjuntura, o Brasil deveria cumprir um importante papel: o de ajudar a reforçar a língua e a cultura portuguesas em África.

Os discursos de irmandade no além-mar e de certa proximidade cultural entre o Brasil e a chamada África Portuguesa ganharam uniformidade com o luso-tropicalismo. Gilberto Freyre, que a convite de Salazar ${ }^{9}$ visitou todo o território Ultramarino Português em 1951, ressaltava em sua obra "Um brasileiro em terras portuguesas", de 1954, que em Cabo Verde um brasileiro se sentia no Brasil e, consequentemente, em Portugal. $\mathrm{O}$ autor também enfatizava as similitudes entre as ilhas de Cabo Verde e a região do Ceará. Esses discursos exerceram grande influência nos governos e em círculos políticos nacionais e voltou a tomar forma com a fundação da Comunidade de Países de Língua Portuguesa (CPLP).

O início de toda uma política de aproximação entre os países de língua portuguesa ganhou força durante o governo do então presidente José Sarney, que em 1989 reuniu em São Luís, Maranhão, chefes de Estado dos governos brasileiro, português e de países africanos. O evento buscava discutir os objetivos comuns que integrariam o Instituto da Língua Portuguesa, sediado na Cidade de Praia, em Cabo Verde. Podemos destacar alguns pontos que ficaram decididos na ocasião: a) promover a defesa da Língua Portuguesa, no pressuposto de que se trata de patrimônio comum dos países e povos que a utilizam como língua nacional ou oficial; b) fomentar o enriquecimento e a difusão do idioma como veículo de cultura, educação, informação e de acesso ao conhecimento científico e tecnológico; c) promover o desenvolvimento das relações culturais entre todos os países e povos que utilizam o português; d) encorajar a cooperação, a pesquisa e o intercâmbio de especialistas nos campos da língua e da cultura; e) preservar e difundir o Acordo Ortográfico já assinado e em curso de ratificação (SARAIVA, 1996, p. 228).

O intuito maior da comunidade era que a integração econômica regional pudesse ser operacionalizada, abrindo espaços de aproximação entre os países e que interesses econômicos seriam motivados através de valores políticos e culturais. Assim, a CPLP

\footnotetext{
${ }^{9}$ Chefe do governo português entre os anos de 1932 e 1968.
} 
obteve um importante papel no incentivo e fortalecimento das relações políticas e econômicas entre esses países. Assim, o Brasil se aproximava cada vez mais de Cabo Verde e o primeiro passo para a concretização das trocas comerciais se deu em 1999, momento em que ocorreu o perdão parcial da dívida externa cabo-verdiana com o Brasil e o reescalonamento do pagamento dos valores atrasados ${ }^{10}$.

O débito totalizava quase $50 \%$ da dívida externa do país. Com isso ocorreu uma reabilitação econômica, possibilitando a consolidação de bases para o desenvolvimento e sua inserção na dinâmica internacional. Nesse contexto, o Brasil obteve destaque significativo. Os convênios instituídos também ganharam uma maior projeção a partir dos incentivos da ONU para a realização de acordos internacionais. Todavia, foi no Encontro Brasil-África, ocorrido em 2003, na cidade de Fortaleza, que se deu a concretização dessas trocas. O evento foi realizado pelo governo brasileiro, que objetivava a ampliação das relações turísticas e comerciais com Cabo Verde.

As trocas comerciais têm demonstrado, nos últimos anos, um aumento econômico expressivo entre os dois países. De acordo com dados do Ministério das Relações Exteriores, o comércio bilateral cresceu mais de quatro vezes em cinco anos: passou de US\$ 8,9 milhões em 2003 para mais de US\$ 39 milhões de dólares em 2008, sendo particularmente intenso o fluxo comercial com os Estados de Pernambuco e Ceará. Este último tem se destacado no âmbito da troca comercial, devido à ativação do modal aéreo operado semanalmente pela Empresa de Transportes Aéreos Cabo-Verdianos (TACV), com vôos diretos ligando Fortaleza e Praia, que duram, em média, três horas e meia.

Em 2001, ano de implantação do "modal aéreo", inexistia saldo comercial entre os dois países. Quando realmente se efetivou a primeira rota aérea da TACV Praia-Fortaleza, em 2002, o saldo comercial do Ceará com Cabo Verde era de US\$ 139.551, Free on board, o que correspondia naquela época a $0,026 \%$ das exportações cearenses. Já em 2003 o valor exportado chegou a US\$ (FOB) 568.435 e, em 2004, saltou para US\$ (FOB) 3.121.927, numa clara demonstração do quanto a operatividade do modal aéreo implantado facilitou a relação de comércio com o vizinho africano (MUNIZ, 2008, p. 32).

De acordo com pesquisa, a ativação do "modal aéreo" possuía como finalidade inicial o deslocamento de empresários e investidores interessados em dinamizar as

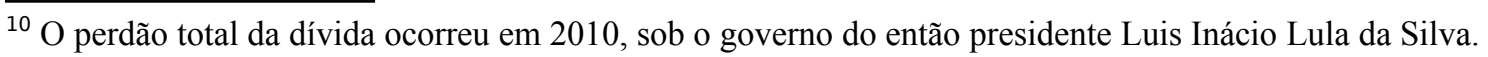
Assim, Cabo Verde deixou de dever cerca de US\$ 3,5 milhões de dólares para o Brasil.
} 
trocas econômicas entre os dois países da costa atlântica. Para fortalecer essa movimentação comercial, foi montada toda uma estrutura que possibilitasse a circulação dessas pessoas pela capital cearense. Os vôos vindos de Cabo Verde eram organizados em grupos de 50 pessoas a cada semana, ciceroneados por gerentes da própria TACV responsáveis pela logística de acompanhamento e orientação de que esses comerciantes necessitavam, tais como: roteiro de locais para compra, hospedagem e alimentação; troca de Dólar por Real; viagens de negócios à região metropolitana e municípios próximos.

Toda essa estrutura havia sido montada para fomentar as trocas comerciais formais entre os dois países. No entanto, com esses incentivos, surgiu um outro tipo de passageiro que, embora detivesse finalidades comerciais, apresentava um perfil diferenciado daquele previsto pelos investidores: as rabidantes cabo-verdianas, impulsionando, sobretudo, o comércio informal, ao adquirirem produtos por preços baratos, em lojas e estabelecimentos sem licença estadual/municipal. No Brasil e, especialmente, no Ceará, o mercado informal tem ganhado relativa importância para a movimentação da economia local. Fortaleza é a quinta cidade mais populosa do país, com 2.505.554 habitantes (dados IBGE 2009), perdendo apenas para São Paulo, Rio de Janeiro, Salvador e Brasília.

A indústria e o comércio mobilizam a economia da cidade, que possui um PIB anual de R\$19,974 bilhões de reais, um dos mais altos do país. Frente à falta de crédito, de qualificação e de vagas no mercado formal, um aglomerado de trabalhadores ocupa as praças, cruzamentos de ruas, mercados e feiras, vendendo roupas, calçados, lingeries, biquínis e inúmeros outros produtos no centro de Fortaleza. Na guerra pela sobrevivência, a opção pelo mercado informal tem ganhado cada vez mais adeptos e conquistado espaço na concorrência pela venda de produtos, sobretudo, quando se tem um mercado consumidor em ascensão. As rabidantes cabo-verdianas gastam em média, por viagem, entre US\$ 3,5 a 4 mil dólares em compras de produtos. Vejamos, então, como tem se dado toda essa movimentação econômica efetivada por essas mulheres aqui no Brasil.

\section{O comércio informal (trans)atlântico das rabidantes cabo-verdianas no Brasil}

Como já observado, as rabidantes têm um poder fundamental na sociedade cabo-verdiana, especialmente pela comercialização de produtos que acabam por sanar 
em grande parte as necessidades da população. Elas revendem produtos adquiridos em outros países africanos, como Senegal, Gâmbia, Guiné-Conakri e África do Sul; europeus, como Portugal, Holanda e França; e no continente americano, como EUA e Brasil. O comércio com países do exterior é marcado por produtos de cabelo, como é o caso dos EUA; sapatos, que são negociados com a Holanda; e roupas, bijuterias, calçados e lingeries advindos do mercado brasileiro.

Em nosso país, a maioria dos produtos adquiridos é de Fortaleza, no Ceará. Podemos destacar alguns dos principais pontos de compra, como, por exemplo, o Mercado Central, onde é possivel encontrar muitas lojas de confecção, renda de bilro, redes, cerâmicas e todo tipo de artesanto produzido no Estado. Os produtos comercializados são de boa qualidade, em geral, advindos das cooperativas de trabalhadores rurais, localizada no interior do Ceará. $\mathrm{Na}$ realidade, os preços dos produtos comercializados no Mercado Central são relativamente altos, uma vez que estão voltados para os turistas. Essa pode ser uma das justificativas para o baixo percentual de compra desenvolvido por essas mulheres nesse local.

É no Centro de Pequenos Negócios de Vendedores Ambulantes de Fortaleza (CPNVA), ou Beco da Poeira, como é conhecido o espaço, que elas adquirem grande parte dos seus produtos. O local se destaca pela venda de roupas características da moda popular, as chamadas "modinhas", geralmente compostas por peças de malha feminina, influenciadas pelos meios de comunicação, principalmente as novelas ${ }^{11}$. Essas peças, com grande circulação no mercado nacional, servem de referência para as cópias que serão reproduzidas em larga escala, com um material de baixa qualidade e preços mais baratos do que aqueles encontrados nas grandes lojas. O Beco da Poeira não vende apenas produtos femininos, mas roupas masculinas, sapatos, bolsas, lingeries, biquínis, acessórios, celulares, relógios e até ervas medicinais.

O Beco funciona de segunda a sábado, das 7 às 17 horas, em um prédio de dois andares, localizado na Avenida Imperador, no centro da cidade. No térreo ficam as lojas e na parte superior os restaurantes e banheiros. São 2.100 boxes, que medem cerca de $1,5 \mathrm{~m}^{2}$, construídos um ao lado do outro, formando inúmeros corredores estreitos. Em frente a cada um destes, quase sempre estão os comerciantes, sentados em um banquinho de madeira, esperando os clientes. Ao longo de todo o estabelecimento, os vendedores ambulantes oferecem caldos, sucos, água, refrigerantes, picolés e salgados.

${ }^{11}$ As novelas brasileiras são constantemente veiculadas no país e acabam por exercer grande influência sobre a população cabo-verdiana, especialmente no estilo de roupas a serem comercializadas. Para uma análise aprofundada sobre essa questão, ver Pina (2007). 
$\mathrm{Na}$ falta de espaço, os clientes têm que provar as roupas nos corredores, em meio a toda essa movimentação. Ao caminhar pelo local, somos constantemente abordados por mulheres, homens e crianças perguntando qual produto desejamos comprar, ou entregando cartões, demonstrando os objetos por eles comercializados.

Outro ponto de compra das rabidantes, no centro de Fortaleza, é a Praça da Lagoinha, conhecida como "shopchão", onde ficam os pequenos comerciantes, que na falta ou sem condições de pagar pelas barracas e estandes de venda, acabam por vender os seus produtos nas ruas transversais que cortam a avenida principal da cidade. As roupas e acessórios comercializados, em geral, são produzidos pelos próprios ambulantes. Igualmente, encontram-se aquelas pessoas que negociam os artigos confeccionados por costureiras autônomas, que montam pequenas fábricas nos fundos das casas em bairros periféricos. Essas fábricas também são pontos de grande procura pelas rabidantes, por possuírem preços baixos, especialmente as peças de moda íntima.

Além de Fortaleza, São Paulo também tem ganhado destaque dentre os destinos de compras dessas mulheres. Lá as compras são desenvolvidas no Braz, na Rua 25 de Março e no Bom Retiro. Inicialmente, a vinda de um número considerável de mulheres, bem como o grande poder de compra delas aqui no Brasil, no início de 2002, estavam diretamente ligados à ascensão do dólar e, consequente, desvalorização do real. Os produtos saiam por um preço extremamente baixo, possibilitando um lucro considerável, tornando essa atividade bastante lucrativa. No período áureo dessa comercialização, de acordo com Muniz (2008), essas mulheres gastavam em média de 3 a 4,5 mil dólares por viagem.

De acordo com esse autor, elas possuíam incentivos por parte do governo cabo-verdiano e adquiriam empréstimos em alguns bancos. No entanto, nas narrativas das rabidantes, a efetivação das compras no Brasil já não possibilita tantos rendimentos como antes. Vários fatores podem explicar esse fenômeno de recessão: o aumento do dólar, que reduziu drasticamente o poder de compra, assim como o lucro na venda de produtos; a carência de financiamentos; os convênios realizados pelo governo cabo-verdiano com outros países, possibilitando e incentivando as trocas comerciais com esses novos parceiros; e, especialmente, o combate que esses governos têm direcionado ao comércio informal.

Ao realizar pesquisas, observamos que esse tipo de atividade tem sido tratado como um "problema" tanto pelo governo brasileiro como em Cabo Verde. No caso do Brasil, a questão tem exigido uma postura firme por parte dos dirigentes do Estado do 
Ceará que, como havia ressaltado anteriormente, destaca-se como um dos centros de maior incidência do mercado informal no país. Essa situação tem gerado fortes embates e discussões entre os vários setores da economia local. Representantes dos comerciantes formais têm buscado resolver essa situação a partir de ações conjuntas com a iniciativa privada e o setor público, especialmente, com a Prefeitura de Fortaleza, na tentativa de discutir possíveis soluções.

De acordo com o presidente da Associação dos Vendedores Ambulantes Autônomos do Estado do Ceará, Antônio Amaro da Silva, em entrevista ao jornal O Povo, o desemprego é a principal causa para a grande procura pela informalidade. Aliada a isso a falta de qualificação conta muito na hora de conseguir uma vaga de trabalho no comércio formal. Segundo o presidente, a maioria dos vendedores são oriundos do interior do Estado, da agricultura ou da construção civil e muitos destes não possuem qualificação. "No mercado informal, não é preciso qualificação para comprar ou vender e muitas empresas exigem níveis elevados de educação", acrescenta.

Antônio destaca um outro problema que tem dificultado a inserção dessas pessoas no comércio formal: a burocracia e a falta de crédito. "Se houvesse maior incentivo para abrir linha de crédito, por meio de instituições privadas ou públicas, a gente poderia se organizar para legalizar. É necessário a formação de cursos de vendas. Tem que ter estudo". A formalização desse tipo de atividade tem sido exigida pelo Sindicato do Comércio Varejista de Fortaleza (Sindilojas), na medida em que os produtos, que são comercializados pelo setor informal, saem por cerca de $20 \%$ a menos do preço vendido pelos lojistas, o que acaba se configurando, para muitos deles, numa concorrência desleal, pois gera uma significativa queda na venda desses objetos.

Assim como no Brasil, em Cabo Verde o mercado informal tem ganhado destaque nas políticas de combate à pobreza implementadas pelo governo. De acordo com nota do então secretário-geral da Câmara de Comércio, Indústria, Agricultura e Serviços de Barlavento, publicada no dia 10 de setembro de 2009, no jornal econômico OJE de Portugal, o comércio informal é estimulador de práticas ilícitas, além de prejudicar o clima de negócio e afetar a participação do país na Organização Mundial do Comércio. Adriano Cruz defendia a imposição de medidas de controle mais rígidas, já que grande parte das atividades é desenvolvida a partir das licenças facultadas pela câmara municipal e não possuem um perfil empresarial.

Vale ressaltar que ainda existe certa confusão quando se tenta diferenciar o "informal" daquilo que seria "formal". O setor informal é sempre difícil de definir. Em 
geral, considera-se que abrange todas as atividades econômicas que não pagam impostos. No entanto, as fronteiras entre os setores formal e informal ficam ambíguas, na medida em que há grandes empresas "formais" que fogem das suas obrigações fiscais, enquanto que muitos vendedores "informais" pagam diariamente taxas aos agentes municipais. De fato, não existe uma definição realmente satisfatória, mas, de uma forma geral, caracterizam-se como informais as atividades não-licenciadas e constituídas, em grande parte, por atividades de auto-empregos.

As problemáticas referentes às práticas formais e informais não se encerram por aí. Estas últimas em muitos casos estão diretamente ligadas a práticas ilegais e/ou ilícitas. Muniz (2008), ao analisar, a partir de parâmetros jurídicos, a relação entre tributação e transações comerciais internacionais, tendo como base a atividade das rabidantes cabo-verdianas no Estado do Ceará, concluiu que ela não se enquadra em nenhuma regra que regula o comércio exterior. Um dos principais questionamentos diz respeito ao fato de essa prática não se caracterizar nem como exportação direta, quando o próprio produtor-exportador a realiza de modo a estabelecer uma relação sem intermediação com a outra parte compradora; nem indireta, que decorre da relação produtor versus comprador, por meio de um interveniente com fim específico de exportar a mercadoria negociada e devidamente descrita na nota fiscal.

De acordo com o autor, a rabidância não se enquadra em nenhuma dessas opções referentes à condição de exportadores e sim de consumidores normais. Logo, sobre toda e qualquer transação entre essas mulheres e as empresas exportadoras, para caracterizar-se como um ato regular de comércio, deveriam incidir os tributos inerentes à operação. A legislação prevê não incidência e isenção de tributos somente nas operações que destinem mercadoria para o exterior. Portanto, a legislação não considera como exportação o ato de o estrangeiro comprar aqui produtos e conduzir ele próprio para o exterior. $\mathrm{O}$ tratamento tributário e a incidência de impostos são feitas em Cabo Verde, onde são cobrados por peça desembarcada. Isso tem acarretado uma perda significativa por parte do governo brasileiro, no tocante à arrecadação fiscal.

As empresas com as quais essas mulheres comercializam também deixam de pagar os impostos exigidos para essas transações, uma vez que elas comercializam esses produtos aqui em solo brasileiro, mas emitem notas fiscais como se estivessem exportando para Cabo Verde. Outro elemento que merece destaque é a quantidade de objetos e o volume de bagagem despachada sem restrições fiscais pelas rabidantes. Segundo Muniz (2008), somente são considerados bagagem e isentos de impostos, os 
bens cuja quantidade, natureza ou variedade não configurem importação ou exportação com fim comercial. Nesses casos, é a empresa de transporte aéreo que tira proveito, pois exige que seja pago como excesso de bagagem ${ }^{12}$.

\section{Considerações finais}

Ao longo do desenvolvimento do texto, procuramos analisar a relação entre Brasil e Cabo Verde, a partir do comércio (trans)atlântico das rabidantes. Foi possível perceber que a inserção nessa atividade está ligada a diversos fatores, como os altos índices de desigualdade social, a baixa escolaridade e a não qualificação para o trabalho formal, especialmente entre as mulheres. No entanto, para além de questões econômicas, é preciso situar a categoria gênero como aporte teórico, uma vez que carece melhor compreender porque tem ocorrido a feminização dessa atividade.

Não obstante, esse é um fenômeno que tem ganhado destaque na economia desses países e possibilitado a intensa movimentação de pessoas e objetos nos dois lados do atlântico. A informalidade consegue atrair um número considerável de adeptos e a rabidância ganha destaque. Apesar dos governos visarem cercear cada vez mais esta prática, podemos perceber que este é um setor que agrega um número considerável da população cabo-verdiana e brasileira, que esta excluída dos benefícios sociais. É, sobretudo, por intermédio dessa atividade que as rabidantes conseguem garantir o sustento da família.

Por fim, é preciso assinalar que de fato existe uma espécie de estratificação entre essas mulheres, em que podemos destacar aquelas que comercializam produtos adquiridos no âmbito interno e que possuem um menor poder aquisitivo; outras que negociam com os demais países africanos e com o Brasil - nesses casos não existem dificuldades com relação ao visto e nem a barreira da língua; e as que conseguem adquirir produtos nos EUA e Holanda, e que detêm um poder de compra significativo.

\footnotetext{
12 A quantidade de bagagem transportada é tão grande, que é possível identificar uma rabidante no aeroporto de Fortaleza a partir do número de volumes por ela conduzido. Em entrevista realizada com uma dessas mulheres, conseguimos contabilizar 25 caixas e malas, que chamavam a atenção pelos tamanhos.
} 


\section{Referências}

ANDRADE, E. As Ilhas de Cabo Verde da descoberta a independência nacional (1460-1975). Paris, L’Haramattan 1995.

BRASIL. Ministério do Desenvolvimento, Indústria e Comércio Exterior. Disponível em http://www.mdic.gov.br/sitio/. Acessado no dia 17 de maio de 2010.

- Instituto Brasileiro de Geografia e Estatística (IBGE). Disponível em http://www.ibge.gov.br/cidadesat/painel/painel.php?codmun=230440\#. Acessado dia 16 de maio de 2010

CARDOSO, Manuela. (2007). Cabo Verde e São Tomé e Príncipe: educação infra-estruturas como factores de desenvolvimento. Portugal: Rainho \& Neves.

EMBAIXADA DE CABO VERDE NO BRASIL. Disponível em http://www.embcv.org.br/portal/modules/news/idex.php?storytopic=7. Acessado no dia 24 de julho de 2010 . 
FERNANDES, Gabriel. Em busca da Nação. Notas para uma reinterpretação do Cabo Verde crioulo. Florianópolis /Praia, Editora da UFSC e IBNL, 2006.

A diluição da Africa: uma interpretação da saga identitária cabo-verdiana no panorama político (pós) colónia. Florianópolis, Editora da UFSC 2004.

FURTADO, Cláudio. Dimensões da pobreza e da vulnerabilidade da pobreza em Cabo Verde: uma abordagem sistemática e interdisciplinar. Dakar: Codesria, 2008.

FREYRE, Gilberto. Aventura e Rotina: sugestões de uma viagem à procura das constantes portuguesas de caráter e ação. Lisboa: Edições Livros do Brasil, 1954 (a)

. Um brasileiro em terras portuguesas: introdução a uma possível luso-tropicologia acompanhada de conferências e discursos proferidos em Portugal e em terras lusitanas e ex-lusitanas da Ásia, África e Atlântico. Lisboa: edições Livros do Brasil, 1954 (b)

GRASSI, Marzia. Rabidantes: comercio espontâneo transatlântico em Cabo Verde. Portugal: Instituto de Ciências Sociais e Spleen Edições. 2003

GOMES, Simone. Cabo Verde e Brasil: um amor pleno e correspondido. Revista de pós-graduação em Língua Portuguesa, $\mathrm{n}^{\mathbf{0}}$ 9, 2008. Disponível em: http://www.omarrare.uerj.br/numero9/pdfs/simone.pdf. Acessado em 20 de maio de 2010.

JORNAL OJE. Disponível em http://www.oje.pt/noticias/africa/comercio-informal-estimula-o-ilegal-e-prejudica-caboverde-na-omc-diz-camara-de-comercio, acessado no dia 28 de julho de 2010

$\begin{array}{llll}\text { JORNAL } & \mathrm{O} & \text { POVO. } & \text { Disponível }\end{array}$ http://opovo.uol.com.br/opovo/fortaleza282/780284.html acessado dia 17 de maio de 2010.

MONIZ, Elias Alfama. Africanidades versus europeísmos: pelejas culturais e educacionais em Cabo verde. Instituto da Biblioteca Nacional e do Livro (IBNL) Praia, 2009.

MUNIZ, Antônio. Tributação e comércio internacional informal: estudo das relações Cabo-Verde - Ceará. Dissertação de Mestrado. Programa de Pós-graduação em Constitucional. Universidade Federal de Fortaleza, 2008.

PINA, Jaqueline. As influências da Telenovela brasileira no cotidiano de Cabo Verde. Monografia de Graduação. Comunicação Social. Universidade Federal de Juiz de Fora, 2007.

ROCHA, José. Dimensão econômica da integração regional: CEDEAO e o caso de cabo Verde. In: CABRAL e FURTADO (org.) Os Estados-nações e o desafio de integração regional da África do Oeste: o caso de Cabo Verde. Praia: Gráfica da Praia, 2008. 
RODRIGUES, José Honório. Brasil e África: outro horizonte. Rio de Janeiro: Civilização Brasileira, 1961.

SANTANA, Ivo de (2004). A experiência empresarial brasileira na África (1970 a 1990). Salvador: Ponto \& Vírgula, 2004.

SARAIVA, José Flávio Sombra (1996). O Lugar da África: a dimensão atlântica da política externa brasileira de 1946 a nossos dias. Brasília: Universidade de Brasília.

SILVEIRA, Onésio. Conscientização na literatura cabo-verdiana. Lisboa: Casa dos estudantes do Império, 1963.

A democracia em Cabo-Verde. Edições Colibri. 2005.

VLETTER, Fion de. A promoção do sector micro-empresarial urbano em Angola. Luanda: Principia Publicações Universitárias e Científicas, 2002. 